This is an Accepted Manuscript version of the following article, accepted for publication in Transcultural Psychiatry. Roland Littlewood, Sushrut Jadhav \& Andrew G. Ryder (2007): A cross-national study of the stigmatization of severe psychiatric illness: historical review, methodological considerations and development of the questionnaire, Transcultural Psychiatry, 44(2), 171-202, DOI:

10.1177/1363461507077720. Copyright (C2007. It is deposited under the terms of the Creative Commons Attribution-NonCommercial-License (http://creativecommons.org/licenses/by-nc/4.0/), which permits non-commercial re-use, distribution, and reproduction in any medium, provided the original work is properly cited.

(c) (1)

\title{
A cross-national study of the stigmatization of severe psychiatric illness: historical review, methodological considerations and development of the questionnaire.
}

\author{
Roland Littlewood ${ }^{a}$ and Sushrut Jadhav ${ }^{a}$ \& Andrew G. Ryder ${ }^{b}$ \\ ${ }^{a}$ University College London \\ ${ }^{b}$ Concordia University Montreal
}

\begin{abstract}
Despite their potential significance for public policy and health provision in different societies, popular conceptualizations of and social responses to severe psychiatric illness remain relatively unexamined. Two general research procedures may be identified: (1) the anthropological approach uses ethnographic methods to look at explicit categorizations, and (2) the sociological approach employs quantitative survey methods to examine the public 'stigma' of psychiatric illness. This article reviews methodological and conceptual approaches to the study of stigma and describes the development of an ethnographically grounded questionnaire to examine 'stigmatization' from data in different cultures. The difficulties of achieving crosscultural comparability of meaning are discussed and the psychometric properties of the instrument are presented.
\end{abstract}

Keywords: ethnographic method, mental illness, stigmatization

There is some evidence that understandings of illness and the consequent social response may determine the prognosis of severe mental illness, independently of any recourse to medical treatment. Indeed, it is now generally accepted that schizophrenia has a better prognosis in some developing countries that in urban industrialized societies (Cohen, 1992). ${ }^{1}$ The smaller proportion of 'poor outcome' patients in some developing countries found in the WHO International Pilot Study of Schizophrenia and the Determinants of Outcome Study (Sartorius et al., 1986), have been explained in terms of the impact of differences in attributing individual responsibility for illness (Cooper \& Sartorius, 1977; Warner, 2004) and different concepts of personal identity (Horwitz, 1982). The value placed on the autonomous individual in industrialized, largely western, cultures has been said to accentuate the social extrusion of chronic psychiatric patients who assume personal responsibility for their illness, and this then makes for a worse prognosis.

Warner (2004) proposed that the course of schizophrenia is related to gender roles, class and social identity, and to labour dynamics. More specifically, unemployment of the mentally ill in capitalist economies leads to a loss of selfesteem, status and independence. In developing societies, the mentally ill individual is less likely to be extruded because of a graduated accommodation of work to ability. Others have argued that non industrialized societies are simply more cohesive, with clear social roles, independent of personal choice, and have categorizations of illness that attribute an external causation to the illness (Waxler, 1979). Nuclear (and thus western) families are said to be less accepting of mental illness than are extended families (El-Islam, 1979; Lefley, 1990). Cooper and Sartorius (1977) suggested that in nonindustrialized societies the environment for schizophrenic patients is, 'supportive and tolerant and [with] little risk of prolonged rejection, isolation, segregation and institutionalisation.' The patterns of immediate family response to schizophrenia that predict a poorer outcome within western societies may also explain this difference in prognosis between societies as a whole (Leff et al., 1987).

\section{Response and Causation}

Horwitz (1982), following Gove and Howell (1974), makes a useful distinction between psychiatric models of stigmatization - in which societies respond by extrusion to the independently existing symptoms of an underlying disease process, and hence the popular conceptualizations may be judged true or false (e.g., Pilgrim \& Rogers, 2005; Sartorius \& Schulze, 2005; Siegler \& Osmond, 1974; Verghese, 1974; Wing, 1978); and the sociological or labelling model in which the illness is itself understood as an outcome of the individual's response to a culturally variable perception of minor deviance, which then shapes this deviance in the direction of a conventionally accepted disease category. ${ }^{2}$ Some sociological interpretations place particular emphasis on the social process of labelling itself (Link \& Phelan, 2001; Scheff, 1974), others stress the way individuals make their identity through or against such ascriptions and extrusions (Eaton \& Weil, 1955; Estroff, 1981; Goffman, 1970; 
Langness \& Levine, 1986; Link, Struening, Neese-Todd, Asmussen, \& Phelan, 2001; Ritsher \& Phelan, 2004).

Whatever the more general cultural and historical influences on local responses to psychiatric illness, it is at the level of individual conceptions of illness (or 'deviance'), in its experience, recognition and immediate consequences, both social and intrapersonal (Ritsher \& Phelan, 2004), that we are likely to find a link between broader economic and cultural meanings and the immediate consequences of identified illness (Crisp, 2004; Haghigat \& Littlewood, 1995).

There are, however, few direct cross-cultural comparisons of local recognition of illness. These studies usually devise a measure of a western attitudinal construct such as 'stigmatization' and then use translated versions of the measure, assuming some comparability of meaning (Askenasy, 1974; Hunt \& McKenna, 1991). An exception is the cross cultural study of Wig and his colleagues, which used vignettes in three developing countries (Malhotra \& Wig, 1975; Wig et al., 1980).

To these methodological approaches, we may counterpose ethnographic (Littlewood, 1990) and historical methods (Fabrega, 1991). Whereas sociological research is usually carried out in western countries, with standardized questionnaires to evaluate attitudes to named categories, ethnographic approaches are more commonly used in Third World countries, and usually aim to describe the shared concepts held by a particular community (Weiss, Jadhav, Raguram, Vounatsou, \& Littlewood, 2001). The methodologies are not mutually exclusive: sociologists have employed ethnographic approaches in western societies (Goffman, 1970), as have anthropologists (Estroff, 1982; Scheper-Hughes, 1979, 1987); and anthropologists and psychiatrists can use previously gathered descriptive and clinical data as the basis for a later questionnaire study of a larger population (Ben-Tovim, 1987; Wagner, Duveen, Themel, \& Verma, 1999; Waxler, 1976).

\section{Ethnographic Approaches}

Although the distinction between 'conceptions of psychiatric illness' and 'response to psychiatric illness' has some heuristic value, it begs the question of actual causation. Even at the pragmatic level of devising questionnaires and rating scales it is not easy to say whether the question is concerned with existing ideas about the 'nature' of psychiatric illness itself or with strategic attitudes to identified psychiatrically ill individuals (Jenkins, 1988). Ethnographically, the distinction may be relatively arbitrary but most studies tend to emphasize one or other position.

Anthropological accounts have concentrated on understandings of psychiatric illness (or analogous patterns) within the general field of local values and social structure (for reviews see Kleinman, 1988; Littlewood, 1990; Marsella \& White, 1982), frequently within the longstanding tradition of cultural relativism with regard to psychopathology (Benedict, 1934). Using a broad framework drawn from medical or cognitive anthropology, they have examined the terminology, nosologies and logical structure of local ethnomedicines, how these relate to other key local cultural concepts, classifications of illness, gender, human action and the natural world, and what notions of the person, theodicy, moral choice and contingency they evoke (Cheung, 1987). ${ }^{3}$ Such studies traditionally examine a well-known small-scale population; they are concerned not with cross-cultural comparison, but with local meaning. Unlike health policy or psychiatric studies, they do not start from a diagnostic construct (e.g., schizophrenia) as the given independent variable and then assess local understandings of it, but examine the broad field of commonsense concepts from which patterns that recall the psychiatrist's field of interest may emerge. From the anthropological perspective, it is not legitimate to make the distinction between the illness (biomedically explained) and its prognosis (sociologically explained) (Littlewood, 1990).

On the vexed question of 'Are psychiatric illnesses universally recognized?' the consensus seems that something akin to chronic schizophrenia is recognized as a distinct and undesirable state, usually but not always aligned to a more general category recalling physical illness, and that it is characterized primarily by continued unintelligibility (Horwitz, 1982; Littlewood, 1990; but see Radden, 1985). In both Trinidad and Boston (USA), relatives of the ill person respond especially to altered appearance and inexplicable actions, and they rate these as the most disturbing (Littlewood, 1988; Scheper-Hughes, 1987). Patterns recalling (and in this type of study we cannot presume identity with) the medical concepts of acute psychosis, mental handicap, personality disorder or neurosis may be understood in a variety of ways: as moral choices, antisocial behaviour, 'physical' or 'psychological' illnesses or simply as points located on a spectrum of possible everyday action and experience.

The analytical schemata applied to such understandings may be quite diverse: 'modern' or 'traditional' ideas (Littlewood, 1988; Orley \& Leff, 1972; Waxler, 1976),'naturalistic' or 'personalistic' aetiology (Foster, 1976), 'instrumental' or 'ultimate' causality (Feinberg, 1990; Littlewood \& Dein, 1995), 'indexical' or 'referential' notions of the person (Gaines, 1982), or simply a quantitative approach that can sometimes avoid anything like an etic/emic dichotomy (Eisenbruch, 1990).

Townsend (1978) has argued from cross-cultural studies, which included both psychiatrists and lay people, that local commonsense conceptions in any society may shape the practical professional response more than the explicit psychiatric theory. Ramon (1985), Sedgwick (1982), and Warner (2004), using historical data, have all proposed that popular and professional categorizations alike are a function of wider changes in notions of moral order. Western notions of psy- 
chiatric illness, as determined by questionnaire interviews, seem relatively unstable over short periods (Murphy, 1976; Persaud, 1991), but it is difficult to identify the specific factors associated with changes in public opinion, whether these are particular health education programmes, general shifts in conceptualizing or empathizing with deviant and unusual patterns, changing prognosis, or just increasing familiarity with patients (Crisp, 2004). McLean (1990) has argued that relatives' understanding of schizophrenia has recently shifted from a notion of family causation to a 'biomedical' model. This is generally presumed to lead to a less stigmatizing response (Crisp, 2004; but see Benning, O’Leary, Avevor, \& Avevor, 2006).

In certain East African societies in the 1960s, a 'naturalistic' explanation went with expectations of a poor prognosis, an 'ultrahuman' explanation with expectations of a better prognosis (Edgerton, 1966). In Britain and Hawaii, also in the 1960s, the reverse was observed (Askenasy, 1974). It is uncertain how much such local ethnomedical categories in themselves actually predict the observable community response. In rural Botswana, madness is more likely to be seen as caused by sorcery than is epilepsy, and less likely to be seen as 'contagious' (and hence presumably less likely to be seen as 'physical'); yet western biomedical treatment is more likely to be sought for schizophrenia than epilepsy (Ben-Tovim, 1987). Nor does what people say they know, or do, necessarily accord with what they do in actual situations. Thus, in India, China, Ireland and elsewhere (Chiu, 1981; McDaniel, 1989; Scheper-Hughes, 1979), one can certainly find distinct oral and written traditions which place a 'positive' value on insanity but it is uncertain whether this results in a more general empathy with, or refusal to extrude, identified patients. Conversely, in Trinidad, a generally elicited rejecting notion of madness may be rather more benign in actual practice (Littlewood, 1988). Whereas in Hawaii, serious psychiatric illness is seen as the intelligible result of social factors, there is still considerable distrust of the patient; in the UK the reverse is true (Askenasy, 1974). Concepts recalling the English word insanity, such as pagol (Bengali) or pissu (Sinhalese), may carry with them some notion of eccentric but meaningful value, but this may be no more than a common but 'weak' connotation, akin to bad in African American English or crazy in British English (Littlewood, 1991a). Such terms have to be considered in actual use: in one situation analogues of insane or mad may refer to subjective experience, in another to observed behaviour. It seems plausible that the subjective connotation is associated with less social extrusion in practice.

Limitations of examining elicited taxonomic constructions alone, along with doubts about their primacy in determining observed social response, have led to the use of more situationally grounded studies (White, 1982). Instead of asking 'How would you distinguish pagol from fits?', more re- cent studies employ inferential logic: 'What other illnesses are caused by these inappropriate family relations? What would you do next for that person given those alternatives? What would make you choose otherwise?' Using vignettes or named categories, one can obtain a hierarchy of resort to different agencies, lay, popular and professional (Kleinman, 1988). Given the interrelationship of elicited conceptualizations (Marsella \& White, 1982), attitudes to hypothetical patients and situations (Edgerton, 1969; Horwitz, 1982), recognition of patients in actual situations (Clausen \& Yarrow, 1955), and the practical contingencies of available social validations and reframings, support systems and therapeutic options (Jenkins, 1988), it is difficult to examine simply 'local theory,' 'recognition' and 'response' as discrete. Conversely, working back from identified patients in psychiatric settings to examine choices about their pathways into care misses the immediacy of actual decision making that could clarify why certain individuals enter a psychiatric pathway while others do not. However, the conventions of anthropological fieldwork - intensive studies of small-scale communities - seldom allow for more than a handful of instances to be observed (Littlewood, 1988). In practice, knowledge of local ideas is derived from anecdotes, hypothetical scenarios and open-ended questions along the lines of 'How would you recognize...?'

Unless named 'universal' (etic, in this instance, psychiatric) categories are used in such studies, it is difficult to place immediate practical decision making in a standardized framework susceptible to cross-cultural study. Anthropology, like other interpretative social sciences, can be faulted for generalizing from local accounts (Littlewood, 1990). The use of a limited number of key informants can restrict the actual number of options recognized in a pluralistic system to certain strategies known to, or preferred by, informants. Even using a vignette in cross-cultural studies of attitudes to psychiatric illness assumes, as does the 'psychiatric model,' that this description has some primacy that can be generalized across societies without too much loss of meaning. The assumption that such questions can be asked with comparable meaning across cultures has been criticized for psychiatric and psychological patterns defined as separately existing entities, even those with a biological component, both in psychiatry (Kleinman, 1988) and psychology (Shweder, 1991). To generalize about local conceptions and responses in a similar way is even more doubtful - similar to drawing general cross-cultural conclusions about 'marriage' or 'religious belief.' This is not to argue that any attempt at a cross-cultural comparison is invalid; merely that the limitations of any such methodology have to be born in mind: any question we can ask in different languages, in different societies and under different economic assumptions, will inevitably transform local meanings, social context and political process. Any comparative attempt will single out that which does appear to 
be translatable or transferable across cultures, and will thus emphasize the apparently universal over the diverse.

\section{Stigmatization and Sociological Approaches}

The most obvious point of departure for practical crosscultural comparison might seem to be the idea of 'stigma' (Byrne, 2001; Crisp, Gelder, Rix, Meltzer, \& Rowlands, 2002; Porter, 1998). Following its classical Greek denotation as the external marks by which slaves and criminals could be recognized, stigma presumes, however, the external marking of an illness or other identified condition rather than any complex conceptualization of it. Another difficulty is that the term carries with it certain specific sociological assumptions about illness causality, which derive principally from labelling and deviancy theory. In these theories, the external marking actually determines the illness.

In both usages, stigma carries with it certain assumptions about shared moral values and the nature of illness (e.g., Ainlay, Becker, \& Coleman, 1986; Goffman, 1970). The sociological idea of stigma developed as part of a continuing twentieth-century debate about the status of the mentally ill in western society, in particular in the USA. Originating in the Mental Hygiene Movement's ideas of mental health in terms of self-sufficient autonomy articulating entrepreneurial values (Davis, 1938), a large number of public 'mental health' programmes have promoted personal responsibility for psychiatric illness, encouraging recognition of it and early recourse to psychiatric services (Clausen, 1981), an approach now termed 'primary prevention' (Caplan, 1964; Swift, 1980). Programmes of 'positive mental health' have emphasized autonomy, self-actualization and 'environmental mastery' (Jahoda, 1958). The American medicalization of child-rearing, social dissent, strikes and revolutionary movements (Davis, 1938) may be less salient recently, but an emphasis on public education in parenting, adolescence, sexuality and delinquency as issues of 'health education' has continued (Price, Ketterer, Bader, \& Monahan, 1980). These assume that even severe psychiatric illness can be actively prevented, or at least dramatically limited ('secondary' and 'tertiary' prevention) by educating a public whose views on mental illness have been identified as 'a patchwork of half-truths...fallacies and inconsistencies' (Cumming \& Cumming, 1955). Eliding what one might distinguish as the ethical, the medical and the educational, popular understandings of illness have been read as simply perverse and untrue, a consequence of 'fear, ignorance and guilt' (Cumming \& Cumming, 1955).

There are now a large number of empirical studies of attitudes to the mentally ill in the USA which examine how the public perception of their presumed violence or other antisocial patterns, or their gender, class, social and personal distance, affect the social response to an identified illness, limiting the autonomy of the individual (Clausen, 1981; Crocetti,
Spiro, \& Siassi, 1974; Freeman \& Simmons, 1961; Hollingshead \& Redlich 1958; C.M.U. Maclean, 1967; Nunnally, 1961; Persaud, 1991; Price et al., 1980; Schwartz, Myers, \& Astracian, 1974; Whately, 1959). Similar studies have been conducted in Britain (for reviews see Crisp, 2004). Even social scientists critical of current psychiatric practice retain a distinctly moral perspective: with 'goodwill and human decency', an 'enlightened practice of public psychiatry' can be achieved (Scheper-Hughes, 1987), providing 'treatment that will facilitate the richest quality of life, foster the most autonomy and self-esteem' (Estroff, 1982). Such contemporary critiques of 'stigmatizing' popular and medical attitudes still assume that acceptance of the mentally ill individual as a moral being is the same as, or at least is closely related to, the alleviation of the psychiatric illness as determined biomedically; hence, the common assumption that the better prognosis of schizophrenia in the Third World can be attributed to less stigmatization (Estroff, 1982; cf. Cohen, 1992).

In perhaps the most well-known popular sociological work, Goffman (1970) defined stigma as, 'the situation of an individual who is disqualified from full acceptance'. Taking an approach akin to that of deviancy theorists like Scheff (1974), he suggested we distinguish between 'actual social ability' (one's real, objectively perceived, social competence) and 'virtual social identity' (one's competence as ascribed by fellow members of one's culture). Although this distinction makes pragmatic sense when the sociological observer's distinction between naturalistic and per sonalistic attributes closely follows commonsense western ideas, as with physical disability, it becomes more problematic with psychiatric illness, unless we take the 'psychiatric model' (Horwitz, 1982) in its 'strong' form - where psychiatric illness is primarily understood as a natural category independent of social contingencies (Littlewood, 1991a). Is a person schizophrenic or do they have schizophrenia? For most psychiatrists and lay people it is difficult here to distinguish the two, making psychiatric illness a suitable subject for sociological deviancy theory, while generating a continuing jural and public debate on the rationality and moral competence of the psychiatric patient (Radden, 1985).

Even with recognizable biological difference or physical disability, Goffman's distinction between 'actual' and 'virtual' social identities is not always easy to perceive, given that he describes how individuals always modify both their public and private selves through such strategies as 'exposing' or 'covering up': the very distinction reverts back to our Cartesian and Kantian distinctions between 'the natural' and 'the social/ psychological' (McLean, 1990; Rorty, 1980). We can employ the notion of stigma, however, not as an actual relationship between 'real' and 'perceived', but as a convenient term for the sort of devalued identity which mental health programmes argue makes for a poorer prognosis in illness through social invalidation (Price et al., 1980), 
and of which patients themselves are quite aware (ScheperHughes, 1987). Horwitz (1982) terms this approach a 'social control model' but it is perhaps more appropriately termed a 'social response' or simply a 'descriptive' account rather than a model of illness.

'Stigmatization' certainly may be a western sociological term, but one that has now passed into the accepted language of public policy debates and indeed into personal selfreflection. Whether it has any prognostic significance as a variable in psychiatric outcomes is uncertain. If we take it as measure of western notions of self-actualization and individuation, its local recognition may actually go along with a worse prognosis (Cooper \& Sartorius, 1977). Murphy (1982) goes so far as to argue that the values of 'positive mental health,' which have informed many of the American and WHO programmes on health education, are those which can be identified most readily in societies with high rates of reported psychiatric illness. The concept of 'stigma' may, however, be related to such more general values as 'tolerance' and 'acceptance'. Again, this may not necessarily lead to a better psychiatric outcome in situations where recourse to medical treatment is not popularly recognized as useful. Indeed, if readiness to accept treatment is an aspect of 'western' ideas of autonomy, then 'treatment' may be associated with a worse prognosis because of associated nonbiomedical factors.

\section{Development of a Stigmatization Questionnaire}

Objections to a comparative study of social reactions to a defined category (like those to determining a category itself across cultures) are based on the reasonable ground that they are premature until we have more basic information about how categories are generated locally within their full context of meaning. However, the question of validity is not simply about the 'nature' of such units, but about how they are used and interpreted. The project described here is to be taken then, not as an attempt to deter mine the 'nature' or level of stigmatization as an actual practice, but as a starting point to examine pragmatic questions that bear on the acceptability of current western notions of mental health.

\section{A Working Definition of Stigma}

The working definition of 'stigma' in the collaborative project described here is descriptive, derived from the recent sociological and mental health literature (Clausen, 1981; Davies \& Morris, 1989; Goffman, 1970; Link \& Phelan, 2001; Scheff, 1974; Spitzer \& Denzin, 1968), but it follows Horwitz (1982) in minimizing any aetiological assumptions:

The perception of a response to people who have the particular characteristic under study (here psychiatric illness) which restricts them to a lesser participation in everyday civil and family life than others, and which devalues them as of lesser moral or social worth. Such attitudes and responses are manifest in personal relations through avoidance, segregation, extrusion from the family and public participation, or punishment; while they may be manifest implicitly or explicitly in official policies or customary assumptions. Stigma may be represented in particular notions of contagion, violence, attractiveness, incompleteness, sexuality, heredity or through other ideas. These may be developed more formally in popular systems of medicine, psychology or ethics.

Although derived directly from western academic thinking and assumptions, and encompassing both the psychiatric emphasis on extrusion, and the sociological emphasis on a devalued identity, the definition attempted to attain a fair degree of cross-cultural resonance. While dealing with moral values it avoided the sort of explicit criticism of public responses common in the sociological and health policy literature ('negative', 'moralistic', 'harsh': e.g., Beiser et al., 1987). Nevertheless such terms as 'devalued' and 'extrusion' retained some evaluative loading, which was unavoidable without recourse to sociological terms that might be incomprehensible to many of the project's respondents.

The working definition assumes some abstracted idea of full moral, legal and customary status, independent of variations in caste, class, gender, economic power, etc. Such an abstraction is arguably a western legal and academic fiction, closely tied to contemporary notions of individuality. It provoked questions from respondents in Sri Lanka (less so in Britain or Trinidad) in the pilot study of the vignette used along the lines of: 'What responsibility did the family take?', 'Does the person in question come from $\mathrm{X}$ ethnic group/class/professional group?'

It was intended that the working definition of stigma would encompass: local ideas of moral justice and retribution, a perceived absence of both self-control and meeting shared obligations. It would refer to both physical and social consequences of the condition, and practical disability, to varying tolerance of the undesired, to dangerousness (violence or incompetence), incurability, ugliness, ungainliness, gaucheness, or physical dysfunction; to personal and family shame. It would argue an arbitrary affliction with no shared valid meaning, and individuals would be perceived as a burden on others (directly through personal relations or as diminishing some accessible but limited stock of assets - housing, land, food, wells, public funding, access to other basic facilities). It would encompass similar meanings to those in the sociological use of terms like stigmatization, alienation, invalidation, delegitimization, extrusion, prejudice, rejection, segregation and negative evaluation. It 
would exclude responses to minorities who may be said to be stigmatized for possessing characteristics that would otherwise be desired by the community as a whole, such as wealth or certain skills (Goffman, 1970).

An advantage of such a broad concept of stigma is that its different attributes may each be compared with responses to a number of other statuses besides mental illness: to certain social classes, genders, ethnic or religious groups, the physically disadvantaged, those with unpopular social, sexual or political practices or ideas, migrants and the socially mobile (Link \& Phelan, 2001; Townsend, 1979). We cannot presume in advance a causal sequence from concept to attitude and thence to practical stigmatization and economic extrusion, in the way 'public attitude' surveys assume. Abstract conceptualizations and the way they are used may be a consequence of economic activity at a particular time, which itself demands justifications of employment capability that may be related to gender, ethnicity or illness (Haghigat, 2001; Haghigat \& Littlewood, 1995). For different communities, one or other characteristic - violence, unintelligibility, loss of economic role - may be identified as having a particular salience, either because it is more common or because it is selectively sought in those already identified as ill. For example, using the Relative's Rating of Symptoms and Social Behaviour Schedule, patients with schizophrenia in Ibadan are perceived as suspicious, whereas those in Agra are viewed as self-centred (Katz et al., 1988).

\section{Measuring Stigma}

Stigmatization, as an analytical description, is unlikely to be identified along a single smooth local gradient. Categories of illness, for example, often show discrete boundaries, and thus a particular society may have a low tolerance of 'minor psychiatric illness' but without much less tolerance of 'major psychiatric illness' (to use the medical parameter), whereas another might easily accommodate levels of slightly deviant behaviour but at 'high' levels, switch to a more extruding attitude. The first perspective has been argued to be characteristic of the western middle-class, the second of the western working-class (Horwitz, 1982). This may explain the seeming paradox in the autonomy-stigmatization argument: if western societies particularly value autonomy, then why should they have more stigmatizing attitudes, if stigmatization is a reduction of autonomy for the mentally ill? Because a group's increased autonomy for its identified members may be defined against reduced autonomy for nonmembers. Waxler (1976) argues that such conceptual boundaries represent a group's own boundedness and cohesion, such that in 'tight' traditional societies minor deviance is to be incorporated but certain actions will breach the bounds altogether and the individual is extruded. Murphy (1976) too argues that in homogeneous societies, there is greater 'emotional tolerance'; he implies that the migration to Britain from New Commonwealth countries is likely to make the dominant Whites less tolerant of mental illness. There is, however, some evidence that the 'high threshold' of tolerance among lay people (Cumming \& Cumming, 1955) is an artefact of professional perception of the population or at least is identified within a potentially medicalized or penal framework (Crocetti et al., 1974): the observed population's 'boundaries' of normality in this case are actually determined by the same social process of which the observation is a part, given that the attempt to understand (and change) local perceptions itself takes place in a public psychiatric programme that identifies and treats the patients. Nonetheless, ethnographic studies, like social attitude studies, find different thresholds and boundaries for different subgroups: in 1950s America, middle-class relatives of patients were more likely to feel themselves stigmatized than were working class relatives (Freeman \& Simmons, 1961). In Maharastra, India, mentally ill women are 'concealed', whereas family boundaries for men are already more 'open' and allow help to be solicited from outside; at the same time, their female relatives 'take on' personal responsibility for the illness on behalf of the sick men through their understanding of others' causation (Skultans, 1991). Middle-class respondents in Patna, India, see minor mental illness (manorog) as to be treated in the family, while more serious illness (pagalpan) is to be dealt with externally (Wagner et al., 1999).

Western studies of attitudes to psychiatric illness have often asked participants to respond to named categories of disease or diagnostic labels (Askenasy, 1974; Beiser et al., 1987; Cumming \& Cumming, 1955; Maclean, 1967, 1969). In one of the few cross-cultural studies to look at 'stigmatization' with this method, Davies and Morris (1989) compared English, Bengali and Thai evaluations of 40 ICD disease categories on a six-item questionnaire (unpleasant to look at, unpleasant smell, contagiousness, affects quality of relationships with identified individual, affects personality of individual, makes individual unpredictable and threatening). Each item was rated on a linear analogue scale and summed to produce an overall score. They found similar rank orders in the three countries, with 'schizophrenia' less stigmatizing than rabies, alcoholism and drug addiction, and conclude that:

If the concept of stigma is culturally determined we would have expected different rank orders in different cultures. This was not the case in our survey, which would support the hypothesis that the origins of stigma lie in more fundamental attitudes which do not vary with culture. It might be that the emotions aroused by stigmatizing disease are protective to the group. (Davies \& Morris, 1989, p. 121)

However, current perspectives in cross-cultural psychiatry would argue that this is an illegitimate conclusion: 'culture' 
is not just that which always varies (a measure of difference), nor can we easily distinguish 'culture' from 'fundamental attitude' and 'emotion' (Littlewood, 1990, 1991a).

\section{Development of the Vignette}

In the present study, rather than present respondents with named psychiatric categories, which might have rather different meanings or be unknown, it was decided to use a short vignette presented in lay terms. Variants were derived simultaneously in three different languages, and the English draft was translated and backtranslated by a number of professional collaborators (see Acknowledgements) working in different countries and with different linguistic and ethnic groups. A consensus arrived at a vignette that made sense at all sites (Appendix), which is a brief account of a young man who could be described as having a schizophrenic illness that responded partly to psychiatric treatment.

\section{Development of the Stigma Questionnaire (1988-1989)}

The development of the Stigma Questionnaire (SQ) began with a pool of 123 propositions and/or questions related to stigma drawn from a variety of sources:

1. Some 200 ethnographic and historical accounts of local concepts of 'psychiatric illness' (e.g. Bhattacharya, 1986; Chiu, 1981; Edgerton, 1966; Simons, 1978; Sow, 1978) and related phenomena culled from the published literature on all culture areas (Favazza \& Faheem, 1982; Favazza \& Oman, 1977; Littlewood, 1990; Marsella \& White, 1982). (The data in the Human Relations Area Files was not used for lack of specificity in this field.) Language of publication was English, French or Spanish. Concepts appropriate to 'affect' rather than to 'illness' were omitted. This may have lost some key notions of what constituted an 'illness' but was deemed necessary to prevent an unwieldy extension into the extensive literature of ethnopsychology.

2. Thirty-four histories of psychiatric theory and practice (e.g., Dain, 1964), and nonbiomedical accounts of patterns analogous to 'mental illness' either in English or translated into English (e.g., Lloyd, 1950).

3. Content analysis of 142 personal 'explanatory model questionnaires' (Kleinman, 1980) given to psychiatric inpatients and outpatients or their relatives in psychiatric clinics in Birmingham and London (UK), and in Trinidad (West Indies). About one third of the British respondents were members of ethnic minorities; $72 \%$ were given a diagnosis of a psychosis.

4. Patients' own ideas about 'serious psychiatric illness' and 'stigmatization' derived from a weekly clinicalapplied anthropology group on the psychiatric ward of a London teaching hospital over 4 years, written up after each session (Littlewood, 1990). Although this was generally in English about one quarter of the patients were born overseas with a first language other than English.

5. A London user group, to which the first author acted as an advisor, volunteered ideas of popular understandings of 'severe psychiatric illness'; as did medical and social workers from North London (White middle-class population), Barcelona (Spanish and Catalan speakers), Bangalore (Hindi), Calcutta (Bengali), Colombo (Sri Lanka, Sinhalese population), Port-of-Spain (Trinidad, Afro-Caribbean), Birmingham (African-Caribbean, White English, Punjabispeaking population), Bedford (Punjabi speaking population). For non English speaking groups, professionals volunteered these ideas in the local language, which were matched with English analogues or kept in the original language. Patients' understanding of 'stigma' was closer to the symbolic interactionalism of Goffman (1970) than to our own (above), emphasizing the unfairness of the social response and that there was a healthy person 'inside' the illness who could reflect on the consequences of the illness and of others' response to it, and negotiate a new identity.

6. Questions used in previous studies of attitudes to mental illness and stigmatization (Davies \& Morris, 1989; Freeman \& Simmons, 1961; Maclean, 1967, 1969; Orley \& Leff, 1972; Whately, 1959; Wig et al., 1980).

When the question pool was scrutinized, it was evident that there were no clear distinctions among conceptualizations of illness, recognition of illness, response to illness and stigmatization; questions dealing with 'basic conceptualizations' rather than 'attitudes to the mentally ill' were therefore included given that the former may predict the latter in ways not immediately obvious (Edgerton, 1966). ${ }^{4}$ Specific ideas were subsumed under questions that had a higher level of generality (e.g., 'Family are spoiled' (ensorcelled), 'Passes from grandparents', both from Trinidad under 'Passes down in the family'; 'caused by drinking too much alcohol' (various) under 'brought on by himself'; 'ancestral spirits' (Sri Lanka and others named spirits and sorcery) under 'some spirits or an enemy harming him.'). Sometimes, single local ideas were allocated to more than one higher level: for example 'God's wrath' (Trinidad) was allocated to both 'brought on himself' and 'passing down in the family' (Littlewood, 1988). In the process of coding, some higher order categories (e.g., 'bodily weakness' from 'weak blood' among Afro-Caribbeans in Trinidad and London) were felt to have become too vague and were dropped altogether. Concepts of illness that implicated named aetiological agents or 
Table 1

Descriptive statistics for age and education across seven samples.

\begin{tabular}{|c|c|c|c|c|}
\hline & \multicolumn{2}{|c|}{ Age } & \multicolumn{2}{|c|}{ Education } \\
\hline & $M$ & $S D$ & $M$ & $S D$ \\
\hline England & $24.4_{\mathrm{a}}$ & 10.8 & $15.6_{\mathrm{a}, \mathrm{b}}$ & 3.0 \\
\hline Greece & $30.0_{\mathrm{b}}$ & 14.8 & $15.0_{\mathrm{b}, \mathrm{c}}$ & 2.9 \\
\hline Poland & $39.6_{c}$ & 13.1 & $15.0_{\mathrm{b}, \mathrm{c}}$ & 3.5 \\
\hline India & $34.9_{\mathrm{d}}$ & 13.7 & $11.0_{\mathrm{d}}$ & 5.5 \\
\hline Sri Lanka & $29.9_{b}$ & 7.1 & $18.2_{\mathrm{e}}$ & 3.1 \\
\hline Caribbean & $31.6_{b}$ & 12.5 & $16.5_{\mathrm{a}}$ & 12.0 \\
\hline West Africa & $29.5_{b}$ & 8.3 & $14.0_{\mathrm{c}}$ & 4.8 \\
\hline$F$ test & \multicolumn{2}{|c|}{$F(6,1406)=26.58^{*}$} & \multicolumn{2}{|c|}{$F(6,1415)=37.40^{\star}$} \\
\hline
\end{tabular}

Means that share subscripts do not significantly differ on the Least Significant Differences post-hoc test. $* p<.05$.

bodily dysfunctions (e.g., worms in the brain from Edgerton, 1966,'sinking heart' from Krause, 1989, or 'unemployment' and 'dopamine in the brain') were omitted where they could not be subsumed under a higher order category, as were specifically identified social transgressions ('Wife been with another man' from Trinidad) and local classificatory schemata (climatic understandings from Eisenbruch, 1990 and Lloyd, 1950, and a number of patients in different countries; 'strong' and 'weak' from Orley, 1970). Reviews of concepts of illness and its recognition (Marsella \& White, 1982) were then examined to see if any overarching local concepts picked out by medical anthropologists were omitted; it was decided there were none.

Collaborators were then asked to examine the reduced list, consider parallels in their local language and argue the case for excluding items on the grounds of redundancy or local absence of meaning, or for including any new ones. There were no new items but two questions were dropped at this stage for lack of local appropriateness or meaning in one or more countries: 'Could this illness be caused by stress or pressure?'; 'Could this be caused by an imbalance in the body?'. It was agreed that in certain groups there was no close analogue of 'stress' or 'imbalance'.

The summary and the remaining 26 questions with a 4-point Likert scale were initially piloted in London and Port-of-Spain in English with psychiatric patients, mental health professionals, medical students (Hutchinson, Neehall,
Simeon, \& Littlewood, 1999) and the general public to assess comprehensibility and acceptability. The SQ was both selfrated and used with an interviewer reading the questions and eliciting responses. Minor changes were made in word order, and a set of appropriate brief questions on the respondent's social circumstances devised during the field studies.

The current version of the SQ (Appendix) was piloted on student and general population convenience samples in English in London, Birmingham, Bristol, Trinidad, Sri Lanka and India; its English draft was translated into Bengali, Sinhalese and Spanish, and independently backtranslated twice in succession into English, bilingual backtranslators agreed on approximate comparability of meaning, and small pilot studies were then carried out in Colombo in Sinhalese and in Calcutta in Bengali.

\section{Psychometric Properties of the SQ}

The SQ is intended to facilitate both description of attitudes in particular groups and comparison of these attitudes across groups. This latter task can be accomplished both at the level of individual attitudes, and at a composite level, by summing scores across items which, as a group, measure some underlying construct of 'stigma'. The SQ is not primarily intended as a rating scale for comparing scores between different societies; it only provides certain broad compatibilities of response. Scores can be summed within or between groups, either in total or for grouped questions such as those 
LITTLEWOOD ET. AL

Table 2

Eigenvalues from principal components analysis across seven samples.

\begin{tabular}{cccccccc}
\hline Component & England & Greece & Poland & India & Sri Lanka & Caribbean West Africa \\
\hline 1 & 4.115 & 3.535 & 3.461 & 4.049 & 2.636 & 3.476 & 3.067 \\
2 & 1.272 & 1.342 & 1.452 & 1.514 & 1.775 & 1.627 & 1.445 \\
3 & 1.119 & 1.250 & 1.277 & 1.191 & 1.341 & 1.514 & 1.323 \\
4 & 1.018 & 1.053 & 1.222 & 1.140 & 1.190 & 1.181 & 1.151 \\
5 & .933 & .935 & 1.056 & .913 & 1.074 & .987 & 1.076 \\
6 & .861 & .869 & 1.015 & .816 & .969 & .893 & .959 \\
7 & .794 & .770 & .835 & .708 & .847 & .838 & .884 \\
8 & .733 & .741 & .754 & .682 & .821 & .706 & .775 \\
9 & .704 & .670 & .621 & .638 & .710 & .674 & .729 \\
10 & .610 & .661 & .591 & .592 & .661 & .561 & .702 \\
11 & .587 & .579 & .533 & .554 & .604 & .504 & .532 \\
12 & .480 & .568 & .446 & .468 & .496 & .423 & .492 \\
13 & .410 & .527 & .405 & .413 & .467 & .341 & .452 \\
14 & .365 & .500 & .332 & .321 & .409 & .275 & .414 \\
\hline
\end{tabular}

dealing with personal responsibility or with social extrusion. Differences between sub-groups of respondents within a particular cultural group (men versus women, professionals versus peasants) are more significant than differences between cultural groups as a whole, but such gender, class or other differences can themselves be compared cross-culturally, particularly between societies with similar patterns of economic and family organization, and notions of selfhood.

The first wave of data collection, beginning in 1990 and ending in March 2004, yielded a demographically diverse set of ethnocultural samples for the psychometric refinement of the SQ. Data were collected from 2004 participants $(52.7 \%$ male, $47.1 \%$ female), ranging in age from 14 to 83 years, from 15 centres. Within each 'centre', the number of participants from the dominant ethnocultural group was assessed, and centres with at least 100 such participants were retained for further psychometric evaluation. These centres were: England, Greece, Poland, India, Sri Lanka, Caribbean and West Africa. (A later article will provide descriptions of each centre.)

\section{Initial Analyses}

Each item was assessed by the investigators to determine the expected direction of effect, either high stigma or low stigma. As a result of this process, several items were reverse-scored $(2,4,5,11,16,18,19,21)$. Several items were also removed because they were not clearly related to high or low stigma, instead measuring aetiological beliefs that might be related to stigma $(9,12,14,15,23,24)$. These items are retained in the SQ in order to test aetiological hypotheses, but are not scored as part of the composite stigma scale. The remaining items were rescored so that higher scores always represent more stigma. Reliability analysis was first conducted in the combined sample, and itemtotal correlations were observed. Poor items were identified by item-total correlations of $<.20$ (Nunnally \& Bernstein, 1994), suggesting a weak relation between a given item and the construct being measured by the remaining items. Two items, 8 and 13, had poor item-total correlations in the combined sample and were removed from the composite stigma scale. Reliability analyses were then repeated within sample separately. Item 2 had a negative item-total correlation in one sample and item 17 had item-total correlations of $<.20$ in the majority of the samples; these items were therefore also excluded from the composite stigma scale.

\section{Evaluation of the Composite Stigma Score}

Composite stigma scores were calculated by taking the mean of the remaining 14 items for all participants who had provided responses for at least two-thirds of these items (i.e., 
Table 3

Loadings on single component from principal components analyses across seven samples.

\begin{tabular}{rrrrrrrr}
\hline Item & England & Greece & Poland & India & Sri Lanka & Caribbean West Africa \\
\hline 1 & -.459 & -.412 & -.464 & -.564 & -.453 & -.542 & -.369 \\
3 & -.321 & -.278 & -.489 & -.409 & -.138 & -.287 & -.537 \\
4 & .425 & .527 & .433 & .472 & .528 & .453 & .525 \\
5 & .678 & .557 & .425 & .670 & .610 & .352 & .696 \\
6 & -.516 & -.441 & -.477 & -.532 & -.233 & -.338 & -.506 \\
7 & -.362 & -.357 & -.121 & -.525 & -.263 & -.573 & -.066 \\
10 & -.582 & -.433 & -.488 & -.599 & -.389 & -.406 & -.325 \\
11 & .576 & .610 & .421 & .378 & .154 & .659 & .291 \\
16 & .678 & .478 & .547 & .421 & .585 & .579 & .528 \\
18 & .644 & .584 & .590 & .539 & .637 & .499 & .680 \\
19 & .560 & .570 & .632 & .564 & .355 & .491 & .367 \\
20 & -.445 & -.416 & -.489 & -.393 & -.245 & -.417 & -.177 \\
21 & .698 & .698 & .593 & .639 & .620 & .669 & .673 \\
22 & -.470 & -.512 & -.584 & -.695 & -.379 & -.531 & -.269 \\
\hline
\end{tabular}

10 or more items). Participants who answered an insufficient number of items were dropped from further analysis. Descriptive statistics for demographic indicators were computed based on these revised samples. Table 1 gives age and education levels and Table 2 gives other demographic indicators.

The dimensionality of the composite stigma score was evaluated by conducting separate principal components analyses (PCA) within each sample. Kaiser-Meyer-Olkin measures of sampling adequacy ranged from .65 to .82, surpassing the recommended cut-off of .60 (Tabachnick \& Fidell, 1996), and suggesting that the data are appropriate for PCA. Visual inspection of the scree plot supported a single overall component in all seven samples, although the EV $>1$ criterion suggested the possibility of additional components. Table 3 gives the eigenvalues and Table 4 the component loadings. These results suggest that, across samples, there is a clear single component, which may be further subdivided into hierarchically lower order secondary components. Although these secondary components, and their cross-cultural variation, may be of future interest, the existence of this single primary component justifies the development of a single composite stigma score.

Further exploration of the essential unidimensionality of the composite stigma score was conducted using confirmatory factor analysis (CFA), testing the fit of the 14-item set to a single factor model. Root mean square error of approximation (RMSEA) and standardized root mean square residuals (SRMSR) were examined, with acceptable fit to a unidimensional model indicated by coefficients < .10 (Steiger, 1990; Steiger \& Lind, 1980). RMSEA coefficients ranged from .06 to .11, with the Caribbean sample failing to meet the criterion; SRMSR coefficients ranged from .06 to .10, with all samples meeting the criterion. Table 5 lists the parameter estimates. The equivocal results for the Caribbean sample do not necessarily imply multidimensionality, especially as no clear multi component solution emerged from PCA, and may instead be attributable to sample size. These findings do not permit claims that stigma consists solely of a single dimension across cultures, but do suggest that it is reasonable to treat the 14 items of the composite stigma score as a single scale.

The internal reliability of the unidimensional composite stigma score was evaluated using Cronbach's alpha. Alpha was acceptable (i.e. $>$.70) in five of seven samples and marginal (i.e. > .60) in the Sri Lankan and West African samples (Briggs \& Cheek, 1986; Nunnally \& Bernstein, 1994). No items with poor reliability in any of the samples were observed. Note that although there were individual items with inferior PCA loadings or CFA parameters, these items were not consistently poor across all samples and maintained acceptable reliability in each sample. Rather than choosing 
LITTLEWOOD ET. AL

Table 4

Parameter estimates from single-factor confirmatory factor analyses across seven samples.

\begin{tabular}{|c|c|c|c|c|c|c|c|}
\hline Item & England & Greece & Poland & India & Sri Lanka & Caribbean & WestAfrica \\
\hline 1 & $-.279^{*}$ & $-.308^{\star}$ & $-.337^{\star}$ & $-.447^{\star}$ & $-.323^{*}$ & $-.406^{*}$ & $-.294^{*}$ \\
\hline 3 & $-.171^{\star}$ & $-.186^{\star}$ & $-.349^{*}$ & $-.311^{\star}$ & -.094 & -.189 & $-.421^{\star}$ \\
\hline 4 & $.263^{\star}$ & $.435^{\star}$ & $.324^{\star}$ & $.481^{\star}$ & $.400^{*}$ & $.422^{\star}$ & $.507^{\star}$ \\
\hline 5 & $.523^{\star}$ & $.383^{\star}$ & $.248^{\star}$ & $.636^{*}$ & $.350^{*}$ & $.244^{\star}$ & $.708^{\star}$ \\
\hline 6 & $-.335^{\star}$ & $-.300^{*}$ & $-.308^{*}$ & $-.496^{*}$ & $-.164^{*}$ & $-.240^{\star}$ & $-.405^{\star}$ \\
\hline 7 & $-.226^{\star}$ & $-.300^{\star}$ & -.090 & $-.501^{\star}$ & $-.224^{\star}$ & $-.483^{\star}$ & -.030 \\
\hline 10 & $-.372^{\star}$ & $-.423^{\star}$ & $-.445^{\star}$ & $-.610^{*}$ & $-.263^{\star}$ & $-.374^{\star}$ & $-.297^{\star}$ \\
\hline 11 & $.290^{*}$ & $.368^{\star}$ & $.263^{*}$ & $.362^{*}$ & .104 & $.583^{*}$ & $.250^{*}$ \\
\hline 16 & $.467^{\star}$ & $.377^{\star}$ & $.430^{*}$ & $.327^{\star}$ & $.481^{\star}$ & $.567^{\star}$ & $.506^{\star}$ \\
\hline 18 & $.530^{\star}$ & $.465^{\star}$ & $.396^{\star}$ & $.564^{\star}$ & $.481^{\star}$ & $.401^{\star}$ & $.605^{\star}$ \\
\hline 19 & $.345^{\star}$ & $.349^{*}$ & $.528^{\star}$ & $.328^{\star}$ & $.189^{\star}$ & $.379^{\star}$ & $.235^{\star}$ \\
\hline 20 & $-.123^{\star}$ & $-.159^{\star}$ & $-.249^{\star}$ & $-.163^{\star}$ & -.070 & $-.172^{\star}$ & -.055 \\
\hline 21 & $.523^{\star}$ & $.707^{\star}$ & $.494^{*}$ & $.546^{*}$ & $.554^{\star}$ & $.670^{*}$ & $.693^{*}$ \\
\hline 22 & $-.297^{\star}$ & $-.307^{\star}$ & $-.424^{\star}$ & $-.596^{\star}$ & $-.232^{\star}$ & $-.392^{\star}$ & $-.155^{\star}$ \\
\hline
\end{tabular}

$* p<.05$.

only ideal items for the scale, thereby impoverishing the coverage of stigma content, we chose instead to retain inferior items provided that these items were not problematic in several different samples.

\section{Conclusion}

'Stigmatization' is a western analytical term that describes certain understandings and social responses, which have been argued to 'disqualify' a designated individual from full social acceptance. Stigmatization may or may not be an elaborated local idea in itself (as it is for professional respondents), and may itself be particularly tied to western notions of self actualization and personal responsibility.

The vignette used in our development of the Stigma Questionnaire follows from a particular (western and professional) individualized notion of mental illness (Fabrega, 1982) similar to the medical concept of schizophrenia, albeit written in lay terms, and thus restricts any potential diversity. It assumes a (medically conventional) primacy of the illness leading to loss of social competence: folk and sociological models may reverse this sequence (Horwitz, 1982). It is only one of a number of possible vignettes and does not necessarily tell us anything about social response to what we rec- ognize as mental handicap, epilepsy, dementia or neuroses. Nor can we assume it refers to a biomedical reality of which lay informants can have only partial knowledge (Littlewood, 1990).

The difficulty of distinguishing between 'concepts,' 'attitudes' and 'response' in framing the questions suggests that any conclusions should not be assumed to be a measure only of response (as the sociological notion of stigma favours). Certain patterns of relationships between respondent and hypothetical patient may be significant not only as a measure of actual 'social distance' (Horwitz, 1982) or the tendency of close relatives to 'normalize' illness (Clausen, 1981; Clausen \& Yarrow, 1955; Rogler \& Hollingshead, 1965), but be part of the local attribution of responsibility and thus the illness category (Skultans, 1991).

Although the SQ was designed to be widely applicable, the meaning of its items will vary with culture and context. SQ items are not weighted, nor can they be cross-culturally. One or other descriptive element or question may carry a particular significance for a community (Littlewood, 1991b), which significantly determines its understanding of and response to psychiatric illness; these in turn may be a function of the availability, type and acceptability of local services or 'therapy management' (Janzen, 1978) options. Nor can 
responses be taken as some autonomous set of 'beliefs' independent of social and economic context. Items on marriage ability have a greater salience in societies where marriage is a public contract that carries major economic implications for all family members.

Gender is variably significant depending on whether material inheritance, power or family identity is traced through men or women; and depending on the relative social visibility of men or women (Skultans, 1991). We may expect that the reported violence of the patient in the vignette against his father will have variable salience for societies with different levels of tolerated public and domestic violence, filial respect, and psychiatric services (Sartorius et al., 1986). Items relating to psychiatric hospitalization will have a different salience depending on the extent to which hospitalization is already restricted to an identified illness that causes public violence. Omission of questions potentially salient in one society (e.g., relating to caste) but meaningless in another, may miss a significant local course of action. Auditory hallucinations may be more salient in 'individualistic' societies (Fabrega, 1982), while the vignette specifically plays down the possibility of a valid religious experience. Different versions of the vignette (altering gender, age, course of illness, or hypothesized cultural and personal distance from the individual, or omitting recourse to medical treatment) are likely to elicit different responses. The vignette used describes a case which is already 'medicalized' and may thus elicit a more (or less) extruding response than a vignette which does not involve psychiatric treatment (Shepherd, Cooper, Brown, \& Kalton, 1966).

Using a single vignette tells us nothing about the 'threshold' for recognizing a stigmatizing category or responding to it. Again, multiple vignettes are necessary to examine this. In the West the threshold for entering psychiatric hospital may be lower for women than men, whereas the threshold for recognition has the reverse gender bias (Horwitz, 1982) in as much as other factors can be truly held constant (Littlewood, 1991b). Hospital admission figures in Third World societies would argue the reverse: that more men than women are hospitalized suggests a lower threshold for entry into a formal psychiatric role, and perhaps thus for perception of an identified category. The single vignette does not necessarily provide any 'core category' of illness, whether perceived locally or in psychiatric theory.

'Culture' is not something independent of practical economics and power. Given previous assumptions of the primacy of 'cultural beliefs' over local economic constraints, any generalizations about 'culture' (in the popular sense) as a constant can only be drawn after studies in the same population over a period in which services and local economic constraints vary. Cultural conceptualizations and responses are not, however, to be read as static and autonomous manifestations of some rigid and inescapable system of inher- ited values, but as ideas and actions constantly recreated and transformed by individuals under particular conditions of everyday life and who make sense of the world in which they find themselves and who pursue their own interests (Bourdieu, 1977). The format of the SQ vignette and questions (such as the notion of respondent anonymity, agreement with propositions, and the absence of more specific content in the questions) follows certain accepted western procedures of obtaining information about personal and social life, and is perhaps too bound to a notion of role-dependent categorical knowledge to be equivalent in non-western, particularly small-scale nonindustrialized communities. It is an anthropological commonplace that one's understanding of another society or person can never be independent of the process of gaining that understanding.

The SQ was developed with the conviction that sociological (or anthropological) and psychiatric conceptualizations are not independent but complementary (Littlewood, 1990). Although descriptive ethnographic accounts have provided a wealth of useful information about lay understandings of mental illness in relation to local values, they seldom offer any accounts of the different available positions that may be adopted by individuals within a society. While the attitudinal surveys of sociologists do provide this to some extent, they make arbitrary distinctions between 'knowledge,' 'attitude' and 'response' which the anthropological approach argues is mistaken; taking the available culture-specific questionnaires and applying them as such in another society yields doubtful results. The procedure adopted here - using the western model of stigmatization as a conceptual template to order data in different languages and from various written, professional and patient sources - is intended to deal with some of the limitations of the sociological and ethnographic perspectives.

\section{Acknowledgements}

We are indebted to a large number of patients and their relatives, user groups, lay people and professionals in India, Sri Lanka, Trinidad and Britain for their work on the questionnaire. Particularly valuable collaborators have been Dinesh Bhugra, Theresa Borrell, Wakefield Carter, Ajita Chakraborty, Raymond Cochrane, Raveen Hanwala, Cecil Helman, Jafar Kareem, Britt Krause, Robert Littlewood, Nalaka Mendis, John Neehall, Hannah Roberts, Vieda Skultans, Theo Soutzos, and Narendra Wig. Versions of the SQ in Bengali, Sinhala, Spanish and English may be obtained from the first author.

\section{Notes}

1. Earlier writers, with cruder epidemiological data, reported that western societies actually had a better prognosis (Dain, 1964; Soddy \& Ahrenfeldt, 1965). 
2. Regarding schizophrenia, the practical distinction between Horwitz's two models - the sociological, in which the illness is to be understood simply as a consequence of social conceptualizations, and the psychiatric, in which an autonomous disease initiates the social response - has diminished. Few sociologists maintain the former in its 'strong' versions, while the 'weak' form - that serious mental illness as an identified pattern occurs through social perceptions relating to tolerance of certain actions or situations - would be generally agreed by most social psychiatrists. The consensus may be said to be that the resultant illness is both biological and social in aetiology, although emphasis is placed on one or the other depending on disciplinary interest (Estroff, 1982).

3. Patients' own understandings of illness may be quite different from those of their relatives, or from the popular commonsense understandings to which they may recognize themselves as responding (as much as to medical views). For example, although American patient groups' core conceptualizations are closer to a 'sociological' view in emphasizing social response rather than symptoms, relatives' support groups now favour biological theories that place the causal responsibility on biochemical processes if not the patient themselves (Estroff, 1981; McLean, 1990). At present there are no studies on patients' own conceptualizations in non-western societies comparable with the detailed ethnographies of American patients, but one might predict that schizophrenic patients will generally prefer theories that attribute illness causation to processes independent of their own volition.

4. It was even considered by some collaborators that the project should be changed from one on 'stigmatization' to 'concepts of illness' (Eisenbruch, 1990; Foster, 1976). However, we felt that to do this would distort the data already collected in which stigmatization was expressly mentioned to collaborators.

\section{References}

Ainlay, S. C., Becker, G., \& Coleman, C. (1986). The dilemma of difference: A multidisciplinary view of stigma. New York: Plenum Press.

Askenasy, A. R. (1974). Attitudes toward mental patients: A study across cultures. Hague, The Netherlands: Mouton.

Beiser, M., Waxler-Morrison, N., Iacono, W. G., Lin, T.Y., Fleming, J. A. E., \& Husted, J. (1987). A measure of the 'sick' label in psychiatric disorder and physical illness. Social Science $\mathcal{F}$ Medicine, 25, 251-261.

Benedict, R. (1934). Anthropology and the abnormal. Journal of General Psychology, 10, 59-80.
Benning, T. B., O’Leary, M., Avevor, E. A., \& Avevor, E. D. (2006). Biology and stigma (letter). British Journal of Psychiatry, 188, 89.

Ben-Tovim, D. I. (1987). Development psychiatry: Mental health and primary health care in Botswana. London: Tavistock.

Bhattacharya, D. P. (1986). Pagalami: Ethnopsychiatric knowledge in Bengal. New York: Syracuse University South Asian Series Noll.

Bourdieu, P. (1977). Outline of a theory of practice. Cambridge: Cambridge University Press. Briggs, S. R., \& Cheek, J. M. (1986). The role of factor analysis in the development and evaluation of personality scales. Journal of Personality, 54, 106-148. Byrne, P. (2001). Psychiatric stigma. British Journal of Psychiatry, 178, 281-284. Caplan, G. (1964). Principles of preventive psychiatry. New York: Basic Books. Cheung, F. M. (1987). Conceptualisations of psychiatric illness and help-seeking behaviour among Chinese. Culture, Medicine and Psychiatry, 11, 97-106. Chiu, M. L. (1981). Insanity in imperial China: A legal case study. In A. Kleinman \& T.-Y. Lin (Eds.), Normal and abnormal behaviour in Chinese culture (pp. 75-94). Dordrecht, Germany: Reidel.

Clausen, J. (1981). Stigma and mental disorder: Phenomena and terminology. Psychiatry, 44, 287-296.

Clausen, J., \& Yarrow, M. R. (1955). The impact of mental illness on the family [Special issue]. Journal of Social Issues, 11, 1-65.

Cohen, A. (1992). Prognosis for schizophrenia in the Third World: A reevaluation of cross-cultural research. Culture, Medicine and Psychiatry, 16, 53-75.

Cooper, J. E., \& Sartorius, N. (1977). Cultural and temporal variations in schizophrenia: A speculation on the importance of industrialization. British Journal of Psychiatry, 130, $50-55$.

Crisp, A. (2004). Every family in the land: Understanding prejudice and discrimination against people with mental illness. London: Royal Society of Medicine.

Crisp, A. H., Gelder, M. G., Rix, S., Meltzer, H. I., \& Rowlands, L. J. (2002). Stigmatisation of people with mental illness. British Journal of Psychiatry, 177, 4-7.

Crocetti, G. M., Spiro, H. R., \& Siassi, I. (1974). Contemporary attitudes towards mental illness. Pittsburgh, PA: University of Pittsburgh Press.

Cumming, J., \& Cumming, E. (1955). Mental health education in a Canadian community. In B. D. Paul \& W. B. Miller (Eds.), Health, culture and community: Case studies of public reactions to health programs. New York: Russell Sage Foundation.

Dain, N. (1964). Concepts of insanity in the United States 1789-1865. New Brunswick, NJ: Rutgers University Press.

Davies, T. W., \& Morris, A. (1989). A comparative quantification of stigma. Social Work and Social Sciences Review, $1,109-122$. 
Davis, K. (1938). Mental hygiene and the class structure. Psychiatry, 1, 55-65.

Eaton, J. W., \& Weil, R. J. (1955). Culture and mental disorders. Glencoe, IL: Free Press.

Edgerton, R. B. (1966). Conceptions of psychosis in four East African societies. American Anthropologist, 68, 408-425.

Edgerton, R. B. (1969). On the 'recognition' of mental illness. In S. C. Plog \& R. B. Edgerton (Eds.), Changing Perspectives in Mental Illness (pp. 49-72). New York: Holt, Rinehart and Winston.

Eisenbruch, M. (1990). Classification of natural and supernatural causes of mental distress: Development of a mental distress explanatory model questionnaire. Journal of Nervous and Mental Disease, 178, 712-719.

El-Islam, M. F. (1979). A better outlook for schizophrenics living in extended families. British Journal of Psychiatry, 135, 343-347. Estroff, S. E. (1981). Making it crazy: An ethnography of psychiatric clients in an American community. Berkeley: University of California Press. Estroff, S. E. (1982). Long-term psychiatric clients in an American community: Some sociocultural factors in chronic mental illness. In N. Chrisman \& T. W. Maretzki (Eds.), Clinically applied anthropology (pp. 369-393). Dordrecht, Germany: Reidel.

Fabrega, H. (1982). Culture and psychiatric illness: Biomedical and ethnomedical aspects. In A. J. Marsella \& G. M. White (Eds.), Cultural conceptions of mental health and therapy (pp. 39-68). Dordrecht, Germany: Reidel.

Fabrega, H. (1991). Psychiatric stigma in non-Western societies. Comprehensive Psychiatry, 32, 543-551.

Favazza, A., \& Faheem, A. D. (1982). Themes in cultural psychiatry, 1975-1980. Columbia: University of Missouri Press.

Favazza, A., \& Oman, M. (1977). Anthropological and cross-cultural themes in mental health: An annotated bibliography, 1925-1974. Columbia: University of Missouri Press.

Feinberg, R. (1990). Spiritual and natural etiologies on a Polynesian outlier in Papua New Guinea. Social Science $\mathcal{E}$ Medicine, 30, 311-323.

Foster, G. M. (1976). Disease etiologies in non-Western medical systems. American Anthropologist, 78, 773-782.

Freeman, H. E., \& Simmons, O. G. (1961). Feelings of stigma among relatives of former mental patients. Social Problems, 8, 312-321.

Gaines, A. D. (1982). Cultural definitions, behaviour and the person in American psychiatry. In A. J. Marsella \& G. M. White (Eds.), Cultural conceptions of mental health and therapy (pp. 167-192). Dordrecht, Germany: Reidel.

Goffman, E. (1970). Stigma: Notes on the management of spoiled identity. Harmondsworth, UK: Penguin.

Gove, W. R., \& Howell, P. (1974). Individual resources and mental hospitalisation: A comparison and evaluation of the societal reaction and psychiatric perspectives. American Sociological Review, 39, 86-100.

Haghigat, R. (2001). Stigmatisation of schizophrenia. PhD thesis, University College London, UK.

Haghigat, R., \& Littlewood, R. (1995). What should we call patients with schizophrenia? A socio-linguistic analysis. Psychiatric Bulletin, 19, 407-410. Hollingshead, A. B., \& Redlich, F. C. (1958). Social class and mental illness. New York: Wiley.

Horwitz, A. V. (1982). The social control of mental illness. New York: Academic Press.

Hunt, S. M., \& McKenna, S. P. (1991). Cross-cultural measurement of health perceptions. Paper presented at the British Sociological Association Conference on 'Health and Society.'

Hutchinson, G., Neehall, J. E., Simeon, D. T., \& Littlewood, R. (1999). Perceptions about mental illness among the clinical medical students in Trinidad and Tobago. West Indian Medical Journal, 48(2), 81-84.

Jahoda, M. (1958). Current concepts of positive mental health. New York: Basic Books. Janzen, J. M. (1978). The quest for therapy: Medical pluralism in Lower Zaire. Berkeley: University of California Press.

Jenkins, J. H. (1988). Conceptions of schizophrenia as a problem of nerves: A cross-cultural comparison of Mexican-American and Anglo-Americans. Social Science $\mathcal{E}$ Medicine, 26, 1233-1243.

Katz, M. M., Marsella, A., Dube, K. C., Olatawura, M., Takahashi, R., Nakane, Y., Wynne, L. C., Giff, T., Brennan, J., Sartorius, N., \& Jablensky, A. (1988). On the expression of psychosis in different cultures: Schizophrenia in an Indian and in a Nigerian community. Culture, Medicine and Psychiatry, 12, 331-355.

Kleinman, A. (1980). Patients and healers in the context of culture. Berkeley: University of California Press.

Kleinman, A. (1988). Rethinking psychiatry: From cultural category to personal experience. New York: Free Press.

Krause, B. (1989). The sinking heart: A Punjabi conceptualisation of distress. Social Science $\mathcal{F}$ Medicine, 29, 563-575.

Langness, L. L., \& Levine, H. G. (1986). Culture and retardation: Life histories of mildly mentally retarded persons in American society. Dordrecht, Germany: Reidel.

Leff, J. P., Wig, N. N., Ghosh, A., Bedi, H., Meon, D. K., Kuipers, L., Neilsen, J. A., Thestrup, G., Korten, A., Ernberg, G., Day, R., Sartorius, N., \& Jablensky, A. (1987). Expressed emotion and schizophrenia in North India III: Influence of relatives' expressed emotion on the course of schizophrenia in Chandigarh. British Journal of Psychiatry, $151,156-173$.

Lefley, H. (1990). Culture and chronic mental illness. Hospital and Community Psychiatry, 41, 277-286.

Link, B. G., \& Phelan, J. C. (2001). Conceptualising 
stigma. Annual Review of Sociology, 27, 363-385.

Link, B. G., Struening, E. L., Neese-Todd, S., Asmussen, S., \& Phelan, J. C. (2001). The consequence of stigma for the self-esteem of people with mental illnesses. Psychiatric Services, 52, 1621-1626.

Littlewood, R. (1988). From vice to madness: The semantics of naturalistic and personalistic understandings in Trinidad local medicine. Social Science $\mathcal{F}$ Medicine, 27, 129-148.

Littlewood, R. (1990). From categories to contexts: A decade of the 'new cross cultural psychiatry.' British Journal of Psychiatry, 156, 308-327.

Littlewood, R. (1991a). Against pathology: The new psychiatry and its critics. British Journal of Psychiatry, 159, 696-702. Reprinted in R. Littlewood (2002) Pathologies of the west, London: Continuum.

Littlewood, R. (1991b). Psychiatric diagnosis and racial bias: empirical and interpretative approaches. Social Science $\mathcal{E}$ Medicine, 34, 141-149.

Littlewood, R. (1998). Cultural variation in the stigmatization of mental illness. Lancet, 352(9133), 1056-1057.

Littlewood, R., \& Dein, S. (1995). The effectiveness of words: Religion and healing among the Lubavitch of Stamford Hill. Culture, Medicine and Psychiatry, 19, 339-383.

Lloyd, G. E. R. (1950). Hippocratic writings. Oxford: Blackwell. Maclean, C. M. U. (1967). The determination of community attitudes to mental illness. $\mathrm{PhD}$ thesis, University of Edinburgh, UK.

Maclean, U. (1969). Community attitudes to mental illness in Edinburgh. British Journal of Preventative and Social Medicine, 23, 45-52.

Malhotra, H. K., \& Wig, N. N. (1975). Vignettes for attitudinal studies in psychiatry. Indian Journal of Psychiatry, 17, 195-199.

Marsella, A. J., \& White, G. M. (1982). Cultural conceptions of mental health and therapy. Dordrecht, Germany: Reidel.

McDaniel, J. (1989). The madness of the saints: Ecstatic religion in Bengal. Chicago: University of Chicago Press.

McLean, A. (1990). Contradictions in the social production of clinical knowledge: The case of schizophrenia. Social Science $\mathcal{F}$ Medicine, 30, 969-985.

Murphy, H. B. M. (1976). Review of Askenasy. Transcultural Psychiatric Research Review, 13(April), 48-51.

Murphy, H. B. M. (1982). Comparative psychiatry: The international and intercultural distribution of mental illness. Berlin: Springer.

Nunnally, J. (1961). Popular conceptions of mental health. New York: Holt, Reinhart and Winston.

Nunnally, J. C., \& Bernstein, I. H. (1994). Psychometric theory (3rd ed.). New York: McGraw-Hill.

Orley, J. H. (1970). Culture and mental illness: A study from Uganda. Makarere, Uganda: East African Publishing
House.

Orley, J. H., \& Leff, J. P. (1972). The effect of psychiatric education on attitudes to illness among the Ganda. British Journal of Psychiatry, 121, 137-141.

Persaud, R. D. (1991). Report on Mental Health Foundation MORI survey investigating public attitudes to mental health. Psychiatric Bulletin, 15, 164.

Pilgrim, D., \& Rogers, A. (2005). Psychiatrists as social engineers: A study of an anti-stigma campaign. Social Science $\mathcal{E}$ Medicine, 61, 2546-2556.

Porter, R. (1998). Can the stigma of mental illness be changed? Lancet, 352(9133), 1049-1050.

Price, R. H., Ketterer, R. K., Bader, B. C., \& Monahan, J. (1980). Prevention in mental health: Research, policy and practice. Thousand Oaks, CA: SAGE.

Radden, J. (1985). Madness and reason. London: Allen and Unwin.

Ramon, S. (1985). Psychiatry in Britain: Meaning and policy. London: Croom Helm.

Ritsher, J. B., \& Phelan, J. C. (2004). Internalised stigma predicts erosion of morale among psychiatric outpatients. Psychiatry Research, 129, 257-265.

Rogler, L. H., \& Hollingshead, A. B. (1965). Trapped: Families and schizophrenia. New York: Wiley.

Rorty, R. (1980). Philosophy and the mirror of nature. Oxford: Blackwell.

Sartorius, N., Jablensky, A., Korten, A., Ernberg, G., Naker, M., Cooper, J. E., \& Day, R. (1986). Early manifestations and first-contact incidence of schizophrenia in different societies: A preliminary report on the initial evaluation phase of the WHO Collaborative Study on Determinants of Outcome of Severe Mental Disorders. Psychological Medicine, 16, 909-928.

Sartorius, N., \& Schulze, H. (2005). Reducing the stigma of mental illness: A report from a global programme of the World Psychiatric Association. Cambridge: Cambridge University Press.

Scheff, T. J. (1974). The labelling theory of mental illness. American Sociological Review, 30, 444-452.

Scheper-Hughes, N. (1979). Saints, scholars and schizophrenics: Mental illness in rural Ireland. Berkeley: University of California Press.

Scheper-Hughes, N. (1987). 'Mental' in 'Southie': Individual, family and community responses to psychosis in South Boston. Culture, Medicine and Psychiatry, 11, 53-78.

Schwartz, C., Myers, L., \& Astracian, B. (1974). Psychiatric labelling in the rehabilitation of the mental patient. Archives of General Psychiatry, 31, 329-334.

Sedgwick, P. (1982). Psycho politics. London: Pluto.

Shepherd, M., Cooper, M., Brown, A. C., \& Kalton, G. (1966). Psychiatric illness in general practice. Oxford: Oxford University Press. 
Shweder, R. (1991). Thinking through cultures: Explorations in cultural psychology. Cambridge, MA: Harvard University Press.

Siegler, M., \& Osmond, H. (1974). Models of madness, models of medicine. New York: Macmillan.

Simons, B. (1978). Mind and madness in ancient Greece. Ithaca, NY: Cornell University Press.

Skultans, V. (1991). Women and affliction in Maharastra: A hydraulic model of health and illness. Culture, Medicine and Psychiatry, 15, 321-359.

Soddy, K., \& Ahrenfeldt, R. H. (1965). Mental health in a changing world. London: Tavistock.

Sow, I. (1978). Les structures anthropologiques de la folie en Afrique Noire. Paris: Pagot.

Spitzer, S. P., \& Denzin, N. K. (1968). The mental patient: Studies in the sociology of deviance. New York: McGrawHill.

Steiger, J. H. (1990). Structural model evaluation and modification: An interval estimation approach. Multivariate Behavioural Research, 25, 173-180.

Steiger, J. H., \& Lind, J. C. (1980). Statistically-based tests for the number of common factors. Paper presented at the annual spring meeting of the Psychometric Society in Iowa City, May 30. Available with corrections [Accessed 15 June 2006]: www.statpower.net/Steiger\%20Biblio/SteigerLind\%201980.pdf

Swift, C. F. (1980). Primary prevention: Policy and practice. In R. H. Price, R. K. Ketterer, B. C. Bader, \& J. Monahan (Eds.), Prevention in mental health: Research, policy and practice (pp. 207-300). Thousand Oaks, CA: SAGE.

Tabachnick, B. G., \& Fidell, L. S. (1996). Using multivariate statistics (3rd ed.). New York: Harper Collins.

Townsend, J. M. (1978). Cultural conceptions and mental illnesses. Chicago: University of Chicago Press.

Townsend, J. M. (1979). Stereotypes and mental illness: A comparison with ethnic stereotypes. Culture, Medicine and Psychiatry, 3, 205-230.

Verghese, A. (1974). Public attitudes towards mental illness: The Vellore study. Indian Journal of Psychiatry, 16, 8-18.

Wagner, W., Duveen, G., Themel, M., \& Verma, J. (1999). The modernization of tradition: Thinking about madness in Patna, India. Culture and Psychology, 5, 413-445.

Warner, R. (2004). Recovery from schizophrenia: Psychiatry and political economy (3rd ed.). New York: Routledge and Kegan Paul.

Waxler, N. E. (1976). Social change and psychiatric illness in Ceylon: Traditional and modern conceptions of disease and treatment. In W. Lebra (Ed.), Culture bound syndromes, ethnopsychiatry and alternative therapies (pp. 222-240). Honolulu: University Press of Hawaii.

Waxler, N. E. (1979). Is outcome for schizophrenia better in non-industrialised societies? The case of Sri Lanka.
Journal of Nervous and Mental Disease, 167, 144-158.

Weiss, M. G., Jadhav, S., Raguram, R., Vounatsou, P., \& Littlewood, R. (2001). Psychiatric stigma across cultures: local validation in Bangalore and London. Anthropology and Medicine, 8(1), 71-87.

Whately, C. D. (1959). Social attitudes towards discharged mental patients. Social Problems, 6, 313-320.

White, G. M. (1982). The ethnographic study of cultural knowledge of 'mental disorder.' In A. J. Marsella \& G. M. White (Eds.), Cultural conceptions of mental health and therapy (pp. 69-96). Dordrecht, Germany: Reidel.

Wig, N. N., Suleiman, M. A., Routledge, R., Srinivsa Murthy, R., Ladrido-Ignacio, L., Ibrahim, H. H. A., \& Harding, T. W. (1980). Community reactions to mental disorders: A key informant study in three developing countries. Acta Psychiatrica Scandinavica, 61, 111-126.

Wing, J. (1978). Reasoning about madness. Oxford: Oxford University Press.

\section{Appendix}

Stigmatization Questionnaire (English language version) Thank you for your help in answering some questions about a person who becomes ill. It would be helpful for us to know a little about you. Please answer these questions. They are confidential and we do not need your name.

A. Personal details of respondent: gender, age, marital status, ethnic origin, country of birth, first language, occupation, father's occupation, years of education, family's religion, plus "Has a close friend or relative in your own family seen a doctor for emotional or psychological difficulties?" Yes/No

B. Here is a short account of a person who became ill. Please answer the questions about him:

This young man is twenty years old. He is not married and lives with his parents. He is friendly and hardworking. He works in a local factory. One day he becomes ill and starts imagining things that are not true. He cannot do his job properly and eventually loses it. He spends a lot of time by himself. He hears people talking to him when there is no one there. His parents now become anxious but he does not get better. He starts shouting at the voices which he hears, and he tells his family that they themselves are trying to hurt him. On one occasion he hits his father.

The family are very distressed and frightened and do not know what is happening. They ask their neighbours: nobody thinks this is any sort of religious experience. The family take him to the local doctor who tells them the young man is ill, and gives him some tablets. The tablets do not help him. He does not eat properly. He seems puzzled by what is happening. He does not dress himself properly and is often dirty. He 
wanders about and says embarrassing things to people whom he meets in the streets.

His parents do not know what he is talking about. His doctor sends him to hospital where he stays for two months. He gets better on some new tablets but still needs to take them when he leaves hospital. He does not hear the voices anymore, nor does he have the strange ideas, but he is very quiet and stays alone for much of the time. He occasionally talks to himself but is usually polite to his family. He goes often to see his doctor to get his tablets, and wishes to go back to work.

Here are some questions about this person. Each one must be answered by whether you agree with the question:

Yes, very much -Yes, a little -No, not much - No, not at all

Put a tick in the appropriate box for each question. Remember this is not a test of knowledge but about how you really feel personally.

1. Would you be frightened if this man came to live next door to you?

2. Would you be content if he was to work together with you in your workplace? (If you do not have a job, answer as if you did.)

3. Do you think he will get ill again even if he takes the doctor's medicine?

4. Should he take part in meetings of his family which are to make important decisions?

5. Would you be happy if he married your sister?

6. Could he suddenly become physically violent?

7. If he was your brother would it be important not to let other people know that he had been ill, to avoid shame for your family?

8. If your local hospital opens a clinic for people like him in your neighbourhood would you hope the local coun- cil would object? 9. Is the cause of this sort of illness something passing down in the family?

9. Should the doctors tell him not to have any children in case he passes the illness on to them?

10. Should the doctors have let him out of hospital?

11. Is his illness something he might have brought on himself? 13. Should the doctors only let him leave hospital on condition he goes to see them regularly?

12. Do you think a sympathetic family and friends can stop him becoming ill again?

13. Will a sympathetic family be more help to him than regularly taking medicine?

14. Would it be wise for this man to inherit his parents' property? 17. If he becomes ill again do you think it would be better to call the police first rather than the doctor?

15. Would you be happy if this person became the teacher of your children?

16. Will he be able to return to a completely normal life?

17. Should he stay in hospital for his whole life?

18. Would you eat food which he has cooked?

19. Would you avoid talking to him if possible?

20. Might he have any special powers (to heal, to predict future events, to cause illness)?

21. Could this illness be caused by some spirits or an enemy harming him?

22. Has any person you know personally ever had a similar illness? Yes/No

23. Could you give a name to this illness?...

Thank you for your help. Please hand the questionnaire back. 